\title{
A Familial Variant Chromosome in the 13-15 Group
}

\author{
PATRICIA M. LORD and PATRICIA COOKE
}

From the Department of Human Biology and Anatomy, University of Sheffield, and the United Sheffield Hospitals Centre for Human Genetics, Sheffield 10

Court Brown, Jacobs, and Brunton (1965) carried out a survey on 438 randomly chosen persons and demonstrated that $2.9 \%$ of a total of 207 men and $1.3 \%$ of a total of 231 women showed variants in their chromosome complements. The criteria they adopted were as follows.

(1) That the variant chromosome should be observed in most of the cells.

(2) That its presence should be detected in more than one tissue.

(3) That the variant should be present in at least one other member of the family.

In this paper a family is described in which the variant chromosome is a member of the 13-15 group with a marked increase in the length of the short arms (see Fig.). Occasionally the extra material appeared to consist of double satellites. The affected chromosome was observed in a majority of cells in blood and skin of the daughter and in the blood of the father. The father and daughter were physically and mentally normal, which emphasizes the necessity for extreme care in associating minor chromosomal variation with observed physical or mental abnormality. A study of this chromosome was undertaken to examine the limitations of the use of measurement data in chromosome identification, especially in the positioning of a chromosome within its group according to relative length.

Bishop, Leese, and Blank (1965) investigated the position of the late replicating $\mathrm{X}$ chromosome in the $X+6-12$ group in a set of females, by labelling and subsequent measurement. Their investigations were complicated by the fact that either one or other of the $\mathrm{X}$ chromosomes might show a late labelling pattern in a particular cell, so that they were effectively investigating the variation in the position of a pair of chromosomes rather than a single chromosome. They reported that, though the later replicating $X$ showed a modal position of No. 7, it could vary from position 1 to position 14. The

Received June 6, 1966. present case makes it possible to carry this work a stage further with the knowledge that the same chromosome was examined in every cell.

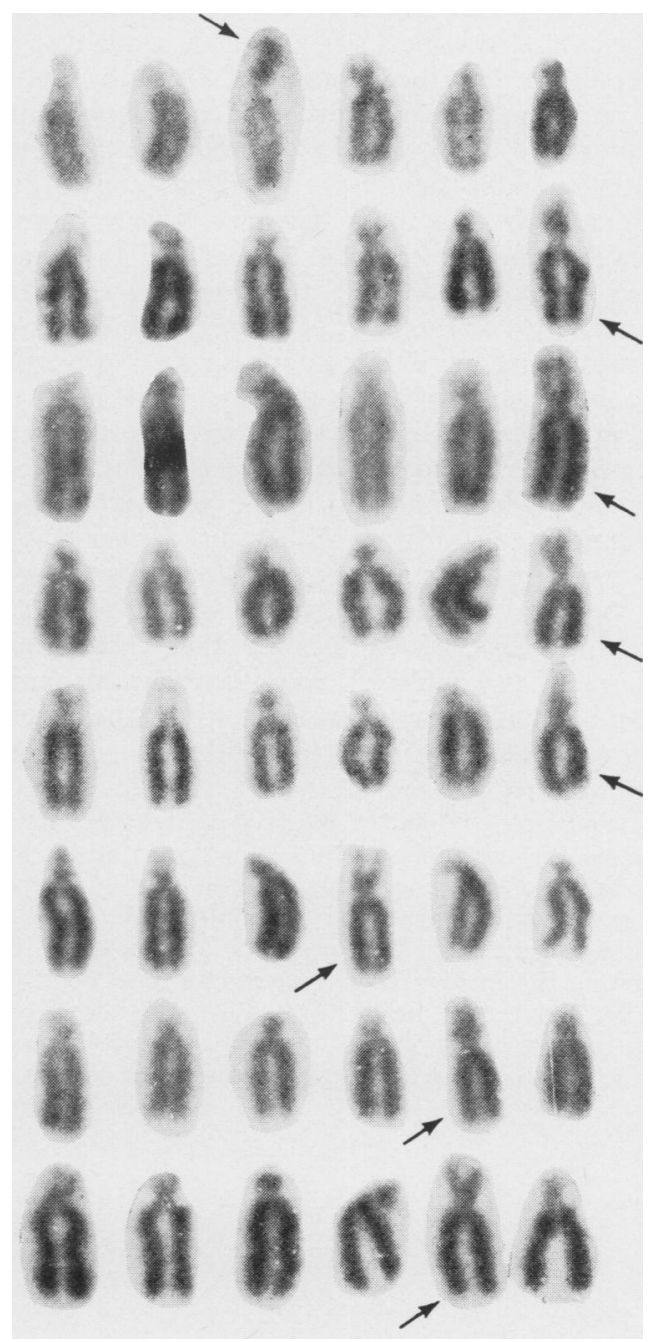

FIG. The variant chromosome. 
TABLE I

MEASUREMENT DATA-LENGTH

\begin{tabular}{|c|c|c|c|c|c|c|}
\hline & Mean Marker & Mean Rest & $\begin{array}{c}\text { Mean } \\
\text { Difference }\end{array}$ & $\begin{array}{l}\text { S.E. Mean } \\
\text { Difference }\end{array}$ & $t$ & $\begin{array}{c}\text { No. of } \\
\text { Observations }\end{array}$ \\
\hline $\begin{array}{l}\text { Daughter's blood } \\
\text { (with colcemid) }\end{array}$ & $28 \cdot 97$ & 31.66 & -2.69 & \pm 0.47 & $5 \cdot 7^{\star}$ & 36 \\
\hline $\begin{array}{l}\text { Daughter's blood } \\
\text { (without colcemid) } \\
\text { Daughter's skin } \\
\text { Father's blood }\end{array}$ & $\begin{array}{l}31 \cdot 33 \\
22 \cdot 80 \\
28 \cdot 90\end{array}$ & $\begin{array}{l}37 \cdot 75 \\
25 \cdot 67 \\
32 \cdot 63\end{array}$ & $\begin{array}{l}-6.42 \\
-2.87 \\
-3.73\end{array}$ & $\begin{array}{l} \pm 0.50 \\
\pm 0.39 \\
\pm 0.44\end{array}$ & $\begin{aligned} 12 \cdot 9^{\star} \\
7 \cdot 3^{\star} \\
8 \cdot 5^{\star}\end{aligned}$ & $\begin{array}{l}36 \\
15 \\
30\end{array}$ \\
\hline
\end{tabular}

${ }^{\star} \mathrm{p}<0.001$

\section{Material and Methods}

Chromosome preparations were made from the daughter's blood (with the use of colcemid in the harvesting process); the daughter's blood (without colcemid); the daughter's skin (with colcemid); and finally from the father's blood (with colcemid).

Photographs of uniform density and enlargement were made of a number of cells from each of the four types of culture. Measurements were made, using an opisometer capable of a resolution of $0.4 \mathrm{~mm}$., on the long arms of all members of the 13-15 group. Each chromatid was measured separately from the tip to the best estimated position of the centromere, and the mean of these measurements was taken for each chromosome. In each cell five parameters were estimated, two relating to length and three to position in the group according to length. The two length measurements were long arm length of the variant chromosome, and the mean long arm length of the remainder of the 13-15 group. An assessment of position was complicated by the fact that in some cells other chromosomes in the group had the same measurement as the variant. In such cases two alternative methods of scoring were used, assigning a 'shorter' position in which the 'true' length of the variant was assumed to be less than that of others of the same measured length, and a 'longer' position when the 'true' length of the variant was assumed to be greater than that of the remainder. Where no such ambiguity existed the position of the variant was referred to as its 'only' position.

\section{Results}

Table I gives a summary of the results of an analysis of the length measurements. In all cases the mean length of the variant chromosome was significantly less than the mean of the remainder of the group. This difference was at its maximum in the culture harvested without the use of colcemid.

Table II gives a summary of the estimated positions of the variant within the 13-15 group in each of the four cultures. It can be seen that, even when in an ambiguous cell the variant was put in its 'longer' position, it tended to take up position 5 or 6. In its 'longer' position it took position 5 or 6 in $82 \%$ of cells over-all. When in its 'shorter' position, this rose to $91 \%$, and in those cells where no measurement ambiguity existed the variant assumed position 5 or 6 in $87 \%$ of cells. In the blood culture harvested without colcemid the length differentiation between chromosomes was much greater than in the other cultures and even in its 'longer' position the variant chromosome took up position 6 in $89 \%$ of cells.

A joint regression analysis was undertaken in an attempt to detect any behavioural differences between the variant chromosome and the rest of the group, with regard to the speed and extent of premetaphase contraction. The best fitting lines for

TABLE II

POSITION

\begin{tabular}{|c|c|c|c|c|c|c|c|c|c|c|c|c|c|c|c|c|c|c|}
\hline & \multicolumn{6}{|c|}{ 'Shorter' } & \multicolumn{6}{|c|}{ 'Longer' } & \multicolumn{6}{|c|}{ 'Only' } \\
\hline & 1 & 2 & 3 & 4 & 5 & 6 & 1 & 2 & 3 & 4 & 5 & 6 & 1 & 2 & 3 & 4 & 5 & 6 \\
\hline $\begin{array}{l}\text { Daughter's blood } \\
\text { (with colcemid) } \\
\text { Daughter's blood } \\
\text { (without colcemid) } \\
\text { Daughter's skin } \\
\text { Father's blood } \\
\end{array}$ & $\begin{array}{l}1 \\
0 \\
0 \\
0\end{array}$ & $\begin{array}{l}0 \\
0 \\
0 \\
1 \\
0\end{array}$ & $\begin{array}{l}6 \\
0 \\
1 \\
0\end{array}$ & $\begin{array}{l}0 \\
0 \\
1\end{array}$ & $\begin{array}{r}4 \\
3 \\
11\end{array}$ & $\begin{array}{l}17 \\
32 \\
10 \\
18\end{array}$ & $\begin{array}{l}\mathbf{0} \\
\mathbf{0} \\
\mathbf{0}\end{array}$ & $\begin{array}{l}0 \\
1 \\
0\end{array}$ & $\begin{array}{l}2 \\
1 \\
1\end{array}$ & $\begin{array}{l}1 \\
0 \\
5\end{array}$ & $\begin{array}{r}3 \\
5 \\
16\end{array}$ & $\begin{array}{r}30 \\
8 \\
8\end{array}$ & $\begin{array}{l}\mathbf{0} \\
\mathbf{0} \\
\mathbf{0}\end{array}$ & $\begin{array}{l}0 \\
1 \\
0\end{array}$ & $\begin{array}{l}0 \\
1 \\
0\end{array}$ & $\begin{array}{l}0 \\
0 \\
1\end{array}$ & $\begin{array}{r}10 \\
2 \\
3 \\
9\end{array}$ & $\begin{array}{r}30 \\
8 \\
8\end{array}$ \\
\hline Total & 1 & 1 & 7 & 2 & 29 & 77 & 1 & 2 & 10 & 8 & 37 & 59 & 1 & 2 & 6 & 3 & 24 & 58 \\
\hline
\end{tabular}


the regression of the length of the variant chromosome (y) on the mean of the remainder of the 13-15 group (x) were calculated for each of the four types of culture separately. The four fitted lines did not differ significantly in slope (pooled $b=0.8555 \pm$ 0.0412 ), but there were position differences which could be related to the length of time that the cultures had been treated with colcemid. The cultures that had been treated with colcemid for an hour and a half (daughter's blood and father's blood with colcemid) showed no significant difference in position, so a single regression equation was derived for these two cultures. Individual regression equations were calculated for the remaining two types of culture.

The regression equations were as follows.

1: Daughter's and father's blood (with colcemid) $y=0.8555 x+2$.

2: Daughter's blood (without colcemid) $\hat{\mathrm{y}}=0.8555 \mathrm{x}-2$.

3: Daughter's skin (with $4 \mathrm{hr}$. colcemid treatment) $\hat{\mathrm{y}}=0.8555 \mathrm{x}-1$.

If the variant chromosome is presumed to contract at the same speed as the rest of the group, and if we can assume that the amount of contraction taking place is proportional to the total amount of chromatic material present, then the expected slope of these lines should approximate to the ratio of the chromosome means in each case. On these criteria the expected slope would be 0.8750 which in fact does not differ significantly from the observed slope $(b=0.8555 \pm 0.0412)$. There is no evidence to indicate that the variant chromosome is behaving differently from the rest of the group. This is, of course, an insensitive comparison, because the rest of the 13-15 group may be showing behavioural variation which is masked by the necessity to pool them.

From the data presented it seems possible to position, by measurement, a chromosome in this group with surprising accuracy. The probability that a chromosome will assume a specific position, with the frequency observed, by chance alone is infinitesimal. In fact, from those observations made without the use of colcemid in the harvesting process, where the range of size variation is large and discrimination more acute, we may say that the 'true' position of the variant chromosome is the smallest in the group.

It may be argued that the variant chromosome is abnormal in that it could be due to a pericentric inversion or have extra satellites, and that the consistency with which it assumes a specific position is a concomitant of its abnormality rather than a true reflection of the accuracy with which measurement can position a chromosome. The regression analysis did not show any evidence of abnormality in behaviour but this may be due to the relative insensitivity of the analysis.

Other variant chromosomes in the 13-15 group are to be examined to determine whether variant chromosomes always tend to be the smallest in this group (either because of behavioural variation or because the same chromosome always tends to be the variant) or whether they can assume any position in the group.

If normal chromosomes behave like this particular variant, then we can put some limits on the accuracy with which we can position, by measurement of length, a normal chromosome within its group. From the present data a chromosome known to be the same one in every cell, if measured without colcemid will be assigned to its 'true' position in more than $80 \%$ of cells, i.e. in a particular cell this chromosome has a better than $80 \%$ chance of being placed in its 'true' position. If this chance is common to other chromosomes (and in some less extensive measurements made on the length of a variant 4-5 this expectation was realized), then in placing, by measurement, a normal chromosome in a particular position, there is at least an $80 \%$ chance of having positioned it correctly.

\section{Summary}

An easily distinguished variant chromosome in the 13-15 group is described in tissues from a phenotypically normal father and daughter.

Its position, by measurement of relative length, within the group was determined with and without the use of colcemid. With colcemid the chromosome was in the position of a member of pair 15 in over $80 \%$ of cells; without the use of colcemid it was the smallest chromosome in the group in nearly $90 \%$ of cells. These results imply that measurement may be an accurate way of positioning chromosomes within their groups.

This study was carried out during the tenure of a Mental Health Research Fund Fellowship.

\section{REFERENCES}

Bishop, A., Leese, M., and Blank, C. E. (1965). The relative length and arm ratio of the human late-replicating $X$ chromosome. f. med. Genet., 2, 107.

Court Brown, W. M., Jacobs, P. A., and Brunton, M. (1965) Chromosome studies on randomly chosen men and women. Lancet, 2, 561 . 